\title{
ПЕРЕВОДНАЯ ПЕЧАТЬ ПО ХЛОПЧАТОБУМАЖНОМУ ТРИКОТАЖНОМУ ПОЛОТНУ
}

\author{
Е. Б. Санжеева, О. В. Козлова, О.И. Одинцова, Т.Н. Зеленкова \\ ЕЛЕНА БАТУЕВНА САНЖЕЕВА - к.т.н., исполнительный директор Российской текстильной компании \\ ООО «БТК Текстиль». Область научных интересов: теория и практика крашения, печати и заключитель- \\ ной отделки текстильных материалов. E-mail: elenasanzheeva1982@gmail.com.
}

ОЛЬГА ВИТАЛЬЕВНА КОЗЛОВА - к.т.н., доиент кафедры химической технологии волокнистых материалов ИГХТУ. Область научных интересов: теория и практика использования отечественных пленкообразуюших полимеров в прочессах колорирования и заключительной отделки текстильных материалов. E-mail:ovk-56@mail.ru.

ОЛЬГА ИВАНОВНА ОДИНЦОВА - д.т.н., заведующчий кафедрой химической технологии волокнистьх материалов ИГХТУ. Область научных интересов: теория и практика создания функциональных текстильных материалов на основе микрокапсулированных систем. E-mail: odolga@yandex.ru.

ТАТЬЯНА НИКОЛАЕВНА ЗЕЛЕНКОВА - инженер-технолог Российской текстильной компании ООО «БТК Текстиль». Область научных интересов: теория и практика получения колористических эффектов на тканях различной химической природы..E-mail: zelenkovatn@mail.ru.

153000 Иваново, пр. Шереметевский, 7, Ивановский государственный химико-технологический университет (ИГХТУ), тел. +7 (4932) 329241, факс: +7 (4932) 417995.

346527, Ростовская область, г. Шахты, ул. Ворошилова, 2, Российская текстильная компания ООО «БТК Текстиль», +7 (8636) 26-96-88, доб.6213, sales@btk-textile.ru.

В работе рассмотрены закономерности протекания процессов закрепления дисперсных красителей на тканях в условиях сублимационной печати в зависимости от природы модификаторов, используемых для предварительной обработки текстильных материалов. Авторами определены оптимальные условия термоперевода красителей на ткань, выбраны наиболее эффективные модификаторы, обеспечиваюшие наиболее высокий выход ивета на ткани, прочность окрасок и достижение экологической безопасности продукиии.

Ключевые слова: акриловые полимеры, сублимационные красители, переводная печать, хлопчатобумажные материалы.

\section{TRANSFER PRINTING ON COTTON KNITS}

\section{E. B. Sanzheeva ${ }^{a}$, O.V. Kozlova ${ }^{\text {}}$, O. I. Odintsova ${ }^{\text {b }}$, T.N. Zelenkova ${ }^{a}$}

2, Voroshilova str., Shakhty, Rostov region, 346527, BTK Textile LLC.

b7, Sheremetievskiy Avenue, Ivanovo, 153000, Russia, Ivanovo State University of Chemistry and Technology. 
The paper considers the regularities of the processes of fixing dispersed dyes on fabrics under conditions of sublimation printing, depending on the nature of the modifiers used for the preliminary processing of textile materials. The authors determined the optimal conditions for thermal transfer of dyes to fabric, selected the most effective modifiers that provide the highest color yield on fabrics, durability of dyes and achieve environmental safety of products.

Keywords: acrylic polymers, sublimation dye, sublimation transfer printing, cotton materials.

Интерес специалистов к переводной термопечати и широкое внедрение этого метода в текстильной промышленности обусловлен рядом преимуществ перед традиционной печатью, а именно: снижением капитальных затрат на оборудование, сохранением производственных площадей, высоким качеством изделий, практически полным отсутствием сточных вод, так как ткани после перевода на нее рисунка не требуют промывки. Технология цифровой и/или переводной печати по целлюлозосодержащим тканям, что является наиболее востребованным в настоящее время, заключается в нанесении сублимационных красителей на специально обработанную поверхность текстильного материала.

В ранних исследованиях авторами показано [1, 2], что одним из методов химической модификации текстильных материалов, который позволил бы повысить восприимчивость хлопчатобумажных текстильных материалов к дисперсным красителям, является обработка её полимерами - модификаторами. Последнее можно реализовать при использовании водных дисперсий полимеров, к которым, помимо получения необходимых колористических свойств, предъявляются специальные требования экологической безопасности и доступности.

В работе предпочтение было отдано синтетическим полимерам - модификаторам акриловой и уретановой природы отечественного производства. Это полимеры серии лакротенов, рузинов, ларусов, а также полимеры на основе уретанов - акваполы. Для сравнения использовали полимеры зарубежных производителей, широко используемые как в сублимационной печати, так и на российских текстильных производствах для отделки текстильных материалов.

Эффективность использования вышеназванных модификаторов в качестве праймеров под термопечать оценивали по комплексу качественных показателей окрасок: насыщенность (интенсивность) цвета, прочность окрасок к трению, степень переноса красителя с бумажной подложки на ткань. Для сублимационного переноса красителей на ткань использован термопресс модели SFS-MO4B.

Объектами исследования выбрано отбеленное хлопчатобумажное трикотажное полотно. В каче- стве красящих веществ выбраны дисперсные красители отечественного производства, обладающие наибольшей сублимационной способностью [3-5]. Это такие дисперсные красители, как алый п/Э, желтый 63 , темно-зеленый и синий К п/э, которые были использованы для печати по бумаге и при выборе оптимальных условий перевода и фиксации красителей на ткани.

На первом этапе с целью выбора наиболее эффективных полимеров в качестве модификаторов текстильного материала под переводную печать проведены широкие испытания, включающие варьирование как температуры, так и длительности процесса термоперевода. Влияние акриловых полимеров различных фирм на насыщенность получаемых окрасок при использовании названных выше дисперсных красителей (в статье - на примере дисперсного синего К) при разных температурно-временных параметрах обработки представлено на рисунках 1а,б и в.

Полученные закономерности свидетельствуют о том, что при всех температурах термообработки максимальное количество красителя переносится на полотно уже при 10 секундах обработки. Однако при $180{ }^{\circ} \mathrm{C}$ значение насыщенности окраски за это время составляет 175 ед, и наивысших значений насыщенности окраски можно достичь только при 60 секундах обработки, тогда как при $200{ }^{\circ} \mathrm{C}$ и $210{ }^{\circ} \mathrm{C}$ максимальная насыщенность окрасок (215-220 ед.) достигается при 10-секундной длительности термообработки и дальнейшее увеличение этого времени не целесообразно.

Кроме акриловых полимеров такие закономерности были получены на серии уретановых полимеров - акваполов (рис. 2 а, б и в), которые также подтвердили выше отмеченные закономерности.

На основании полученных закономерностей показано, что такие полимеры, как Ларус-35, Рузин14И, Рузин-17Б, обладающие остаточной липкостью, Рустан-14 и полиуретан С-612, не позволяющие получить хорошей насыщенности цвета и способствующие получению жесткого грифа, не являются технологичными. Наиболее эффективными из полимеров по показателям насыщенности цвета являются Ларус-21И, Лакротен-Э64, Аквапол-10, Аквапол-11. Эти полимеры способствуют получе- 

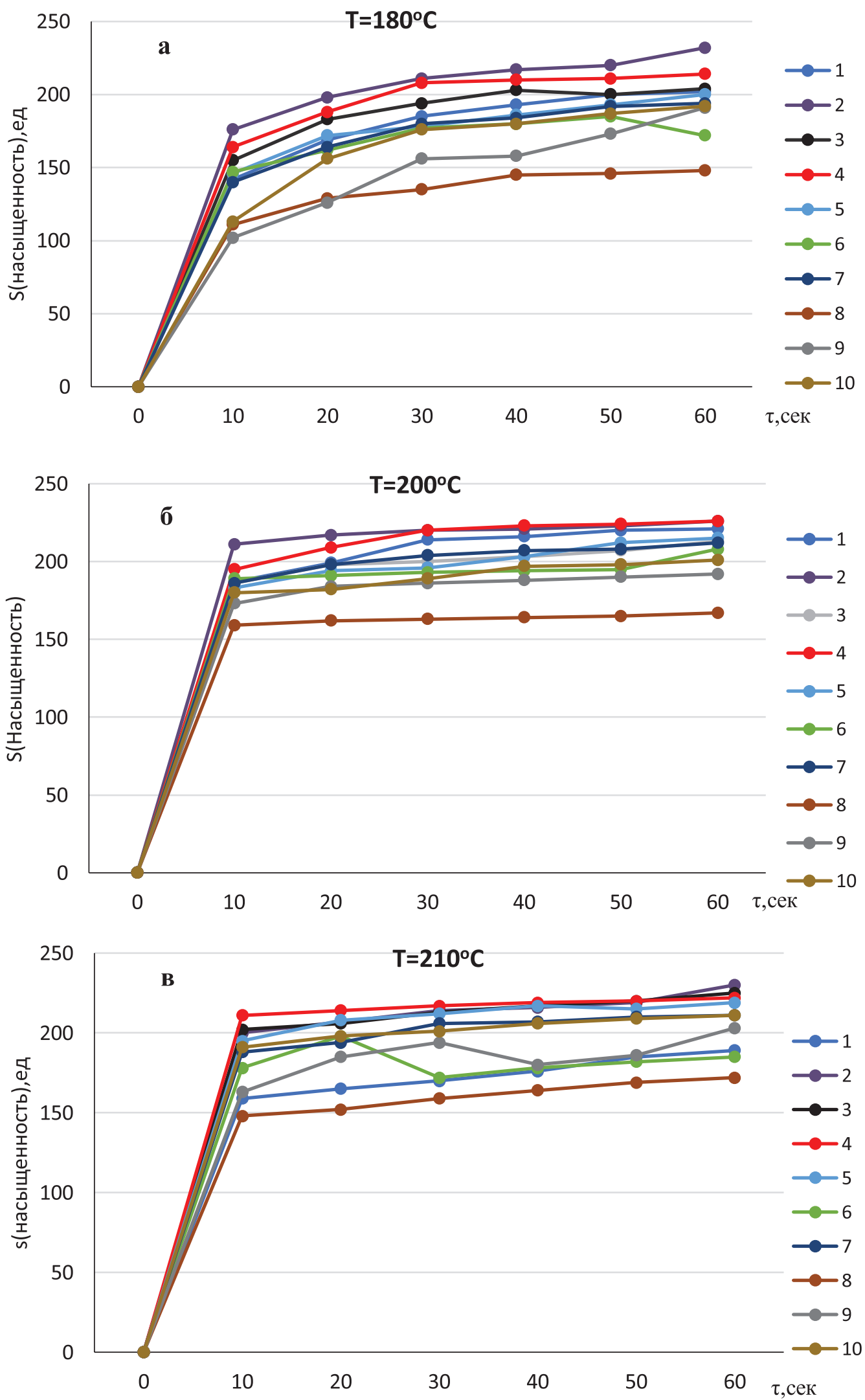

Рис. 1. Результаты печати дисперсным синим К по хлопчатобумажному трикотажу, модифицированному акриловыми полимерами:

1 - Ларус-35; 2 - Рузин-33; 3 - Рузин-14И; 4 - Ларус-21иэ; 5 - Лакротен-Э64; 6-Репеллан КFС; 7 - Эмультекс; 8-C-612; 9 - Рузин- 17Б; 10 - Дистекс при температурах термопереноса: $a-180{ }^{\circ} \mathrm{C} ; 6-200{ }^{\circ} \mathrm{C} ; 6-210{ }^{\circ} \mathrm{C}$ 

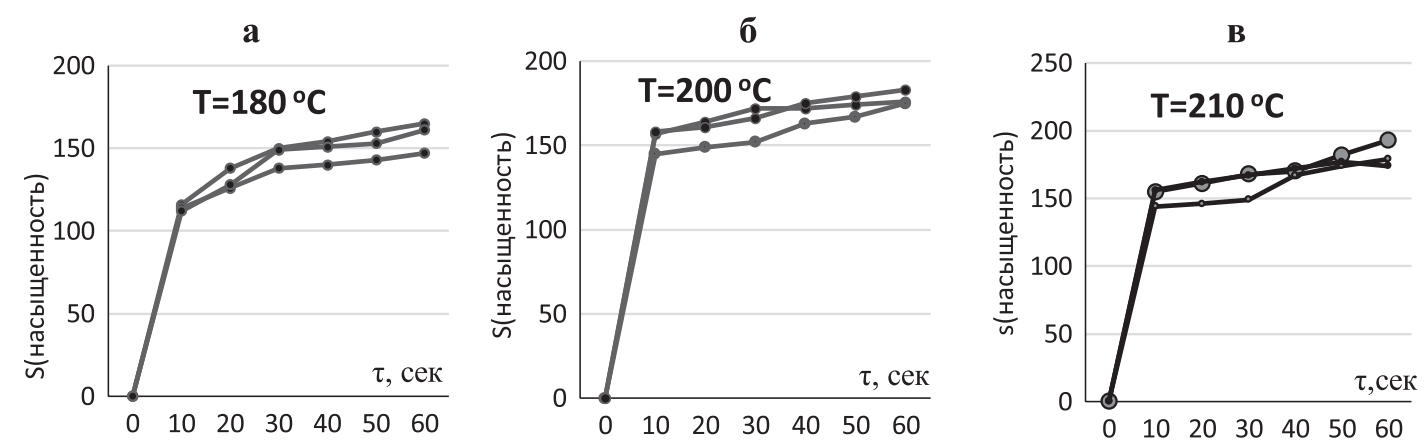

Рис. 2. Результаты печати дисперсным Синим К по ткани, модифицированной полиуретанами:

1 - Аквапол-11; 2 - Аквапол-12; 3 - Аквапол-21 при температурах термопереноса: $a-180{ }^{\circ} \mathrm{C} ; 6-200{ }^{\circ} \mathrm{C} ; 6-210{ }^{\circ} \mathrm{C}$

нию хороших окрасок с высокой интенсивностью (больше 220 ед.) и мягкого грифа [6].

На основе полученных данных к внедрению можно рекомендовать полимер Ларус-21И по экономическим, экологическим параметрам, а также с учётом простоты применения и его доступности. Полиуретаны, которые показали неплохие результаты, являются значительно дороже.

Большим достижением авторов явился подбор смесей красителей для расширения цветовой гаммы окрасок из триады дисперсных красителей.

Интерес представляет оцененная авторами совместимость выбранных красителей при использовании их в сочетании друг с другом. Методика заключается в том, что красители из триады КЗС сочетали попарно в разных соотношениях, печатали оттиски на бумаге и после сушки проводили процесс переводной печати по модифицированному полимером трикотажу.

Совместимость красителей в смесях подтверждается отсутствием разнооттеночности между образцами, обработанными при различных условиях термообработки, а, следовательно, близостью показателей цветового тона, обеспечивающего равномерную сублимацию красителей в текстиль-

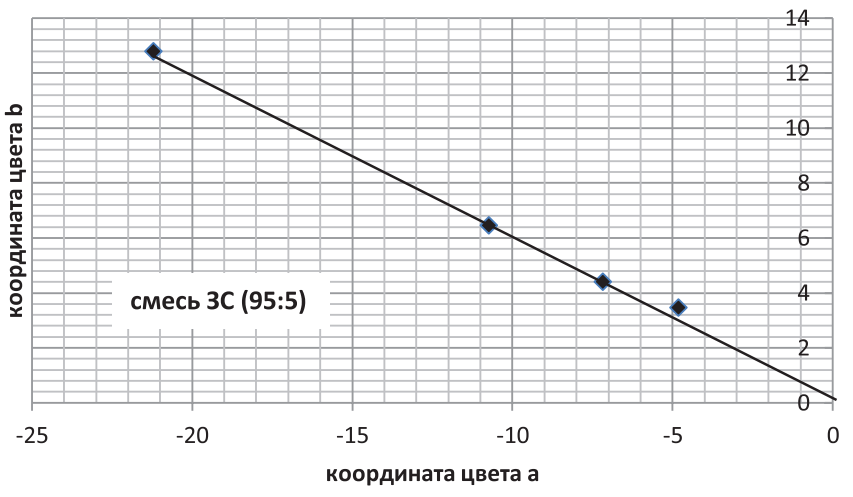

Рис. 3. Координаты цвета a,b смеси дисперсного темно-зеленого и дисперсного синего К при различном времени термоперевода

ный субстрат в процессе печати и прочную там его фиксацию. Красители взяты в разных соотношениях, при температуре печати $-200{ }^{\circ} \mathrm{C}$ и времени термообработки 30 секунд. Перевод красителей с бумаги осуществляли на хлопчатобумажное трикотажное полотно. По данным L, a, b, снятым со спектрофотометра, построены графики (рис. 3 и 4 а,б), на которых можно видеть, что местоположения получаемых цветов практически четко a

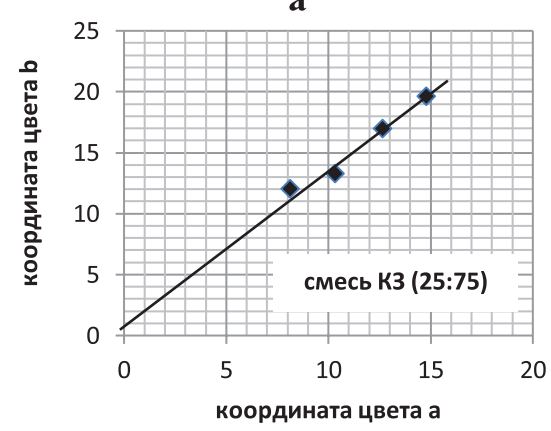

б

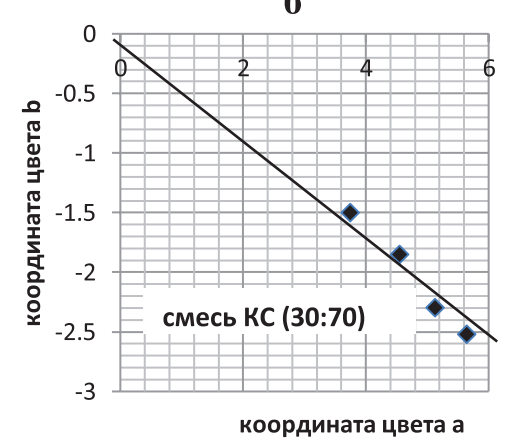

Рис. 4. Координаты цвета a,b смеси дисперсных алого п/э и темно-зеленого (a) и дисперсных алого п/э и синего К (б) при различном времени термоперевода 
укладываются на линии постоянного цветового тона, что подтверждает хорошую совместимость красителей в выбранной триаде по сублимационным свойствам.

Таким образом, реализация технологии переводной печати дисперсными красителями по целлюлозосодержащим текстильным материалам возможна и актуальна. Дальнейшие исследования будут направлены на создание востребованных цветов и расширение базы цветов с помощью выбранной триады красителей.

\section{Вывод}

1. Рассмотрены закономерности протекания процессов закрепления дисперсных красителей на трикотаже в условиях сублимационной печати в присутствии полимерных модификаторов, на основании чего выбран наиболее эффективный препарат Ларус-21И, обеспечивающий сублимационный переход красителя с максимальным выходом красителя на трикотажное полотно и получение хорошей прочности окрасок. Оптимальные условия термоперевода красителей на ткань - 10-20 сек при температуре обработки $200{ }^{\circ} \mathrm{C}$.
2. Оценка совместимости дисперсных красителей в выбранной триаде при использовании их в сочетании друг с другом подтверждает хорошую совместимость красителей по сублимационным свойствам.

\section{Литература}

1. Зеленкова Т.Н., Козлова О.В., Меленчук Е.В., Румянцева B.E. Изв. вузов. Технология текстильной промышленности. 2018. № 2 (374). С.147-152.

2. Зеленкова Т.Н., Козлова О.В., Ширманова В.В.., Хахин С.Н. Рос.хим.ж.(Ж.Рос.хим.об-ва им. Д.И. Менделеева). 2018. T. LXII. №3. C. 18-23.

3. Степанов Б.И. Введение в химию и технологию органических красителей / Б. И. Степанов.- М.: Химия. $-1984-592$ с.

4. Viera Glombikova, Petra Komarkova. Tekstilec. 2014 letn 57(2). P. 133-138.

5. https://www.rolanddga.com/blog/2016/06/02/22/42/3things-you-should-know-about-dye-sublimation 3 Things You Should Know About Dye-Sublimation. May 13, 2015 Roland DGA Public Relations Dye-Sublimation.

6. Козлова О.В., Одинцова О.И., Меленчук Е.В., Федоринов А.С. Российский химический журнал. 2014. T. LVIII. № 2. C. 79-82. 